\title{
A Geografia da Inovação: uma Metodologia de Regionalização das Informações de Gastos em P\&D no Brasil*
}

\author{
Rodrigo Simões \\ Professor do Cedeplar/FACE/UFMG \\ Alessandra Oliveira, Ayane Gitirana e Juliana Cunha \\ Graduação em Economia FACE/UFMG
}

Márcia Campos e Wellington Cruz

Graduação em Economia FACE/UFMG e PET/SESu/MEC

Recebido: 24/8/2004 Aprovado: 25/2/2005

\section{RESUMO}

A análise da produção científica e tecnológica no território brasileiro, a fim tanto de entender os determinantes desta prática no espaço, bem como contribuir para a elaboração de políticas específicas para o fomento destas atividades, tem sido objeto de vários estudos contemporâneos. Estes, geralmente, utilizam-se de variáveis proxies, sendo as mais comumente encontradas na literatura nacional as referentes a publicaçōes de artigos e a registros de patentes. A publicação da Pesquisa Industrial de Inovação Tecnológica - PINTEC, em 2002 abriu a possibilidade de se avaliar o desenvolvimento tecnológico brasileiro a partir de gastos em P\&D, colocando o País no rol daqueles que divulgam estatísticas utilizando metodologia internacionalmente aceita sobre o assunto. Não obstante a disponibilização destas informações pelo Instituto Brasileiro de Geografia e Estatística - IBGE, ainda são poucos os trabalhos que utilizam-nas para um estudo mais detalhado da distribuição espacial da inovação tecnológica brasileira. Diante disso, o presente trabalho faz uso dos dados, agregados por setor, de gastos em P\&D fornecidos pela PINTEC, de informações sobre mão-de-obra qualificada oriundas da Relação Anual de Infor-

* Os autores agradecem as importantes observações e sugestões dos dois pareceristas anônimos. 
mações Sociais - IBGE (RAIS) e dados de patentes do Instituto Nacional de Propriedade Industrial - INPI, para a proposição e estimação de uma metodologia - que utiliza técnica de "ajustes biproporcionais de resíduos", tal como em Bacharach (1970) - que objetiva a regionalização, ao nível das unidades federativas, da atividade inovativa interna às firmas no País.

Palavras-Chave | Estatísticas de P\&D; Metodologia de Regionalização; Brasil

Códigos JEL | O18; R12

\section{ABSTRACT}

The analysis of Brazilian scientific and technological production, both in order to understand the determinants of this practice in space, and to contribute to the construct of specific policies for the fostering of these activities, has been the object of various contemporary studies. These, in general, make use of proxies variables, those concerning article publishing and patent registers being the most commonly found in national literature. The issuance of PINTEC - Industrial Research of Technological Innovation, in 2002 provided the possibility of assessing Brazilian technological development from the point of view of expenses with Research and Development (R\&D), putting our country in the roll of those that disclose statistics using internationally accepted methodology of the subject. Notwithstanding the availability of this information through IBGE - Brazilian Institute for Geography \& Statistics, still very few works use it for a more detailed study of Brazilian technological innovation's special distribution. With this in view, the present work makes use of the sectorial data of expenses in R\&D furnished by PINTEC and of information on skilled labor derived from the Social Information Annual Register - RAIS-IBGE and of data on patentes from the National Institute for Industrial Property - INPI, for the proposal and estimate of a methodology using a technique of "bi-proportional of residues adjustment", as in Bacharach (1970), in order to get the Brazilian regional picture of innovative activity at the level of the country's federal unit.

KEYWORDS I Research and Development Statistics; Regionalization Methodology; Brazil

JEL-CODES $\quad$ O18; R12 


\section{Introdução}

A grande elevação no nível de competição global das últimas décadas deu a certos fatores o poder de ditar o ritmo da nova forma de acumulação capitalista cada vez mais baseada na, assim chamada, economia do conhecimento. $\mathrm{O}$ crescimento do setor produtivo, e das suas economias hospedeiras, se tornou gradativamente mais dependente de relações institucionais específicas que, apesar de não serem inéditas, ganharam maior importância ao fim do século XX, como é o caso das atividades de P\&D internas às firmas. Nesse sentido, as pressōes concorrenciais determinadas por um no mundo fortemente "globalizado" impõem à maior parte das firmas a necessidade de rápida adequação às mudanças tecnológicas obrigando, também e em conseqüência, a maior parte dos países do mundo a aprimorarem o seu aparato institucional. Toda esta discussão é bem tratada na literatura sobre sistemas territoriais de inovação (Abramovitz, 1986; Freeman, 1995).

Nesse sentido, o fato de o Brasil possuir um sistema nacional de inovação imaturo/incompleto (Albuquerque, 1999) evidencia a fragilidade competitiva das empresas localizadas no País, o que se traduz, principalmente, em: a) reduzidos gastos em P\&D; b) pequeno número de patentes registradas domesticamente e no exterior; e c) elevados déficits comerciais setoriais (Alem, 2003).

Apesar de todos estes problemas e limitaçôes do modelo brasileiro, são plenamente justificáveis as tentativas de mensuração do nível de atividades inovativas no Brasil para compararmos ao nível apresentado por outros países, desenvolvidos ou não. Esta tarefa é bem realizada para os países desenvolvidos: o volume de gastos em P\&D dos Estados Unidos, Japão, países da Europa e alguns do sudeste asiático são sistematicamente colhidos e divulgados, bem como utilizados na realização de inúmeros estudos. Contudo, para o caso brasileiro, a Pesquisa Industrial de Inovação Tecnológica - PINTEC, divulgada em 2002, é a primeira tentativa nesse sentido, e a quantidade de pesquisas produzidas a partir dela não se compara, ainda, ao volume de informações disponíveis para as nações supracitadas.

Ademais, existe na literatura internacional pertinente um número razoável de estudos que propõem distribuir espacialmente os gastos realizados com P\&D dentro de seus respectivos países, constituindo uma original "geografia 
da inovação" (Audretsch \& Feldman, 1996). Jaffe et al. (1993), por exemplo, utilizam informações sobre a localização de citaçôes de patentes estadunidense e a localização das próprias patentes, como forma de verificar em que dimensão os transbordamentos de conhecimento, ou de P\&D, são localizados, ou seja, se há ou não uma concentração geográfica destes transbordamentos, devido ao fato de o registro de patentes e suas citaçôes serem concentradas espacialmente. Os autores constatam que há realmente esta concentração nos Estados Unidos, envolvendo o período de 1975 a 1989. Segundo Acs et al. (1992), outros autores trabalharam a relação existente entre a localização de universidades sobre os incrementos na produção de inovações e sobre a ação de registro de patentes concluindo que esta coincidência geográfica é benéfica para o setor privado. Por fim, o trabalho de Audretsch e Feldman (1996) estuda a distribuição da atividade inovativa pelos Estados Unidos, e conclui que nas indústrias em que o transbordamento de conhecimento é mais forte - ou seja, nas indústrias que mais se valem de mão-de-obra altamente qualificada, $P \& D$ interno e pesquisas de universidades - a atividade inovativa tem maior tendência a se concentrar espacialmente.

No Brasil, esforços semelhantes têm tido êxito usando outras variáveis para captar a atividade inovativa no País que não os gastos em P\&D. As mais comuns são o número de patentes registradas junto aos escritórios gestores de propriedade intelectual, nacionais e internacionais, e o número de artigos científicos publicados, o que se convencionou chamar de produção científica. ${ }^{1}$ Albuquerque et al. (2002a), por exemplo, distribuem a atividade inovativa no País, tendo o município como unidade dessa regionalização, por meio de variáveis como número de patentes (registradas por pessoas jurídicas), número de artigos científicos e número de pesquisadores. $\mathrm{O}$ artigo chega, entre outras, à conclusão - fundamentada na observação da participação relativa dos estados do País em termos de Produto Interno Bruto - PIB, distribuição de patentes, artigos e pesquisadores - de que a atividade inovativa se encontra fortemente concentrada no Brasil, na Região Centro-Sul, em especial na Região Sudeste.

Tais resultados são condizentes com aqueles achados por Diniz e Gonçalves

\footnotetext{
Os números de patentes e artigos científicos gerados da atividade inovativa são referidos como variáveis de resultado, enquanto o montante de gastos em P\&D, assim como o total de mão-de-obra empregada e o seu nível de qualificação, são considerados indicadores de insumo. Para detalhes ver FAPESP (2002).
} 
(2000; 2001), segundo os quais apenas cinco localidades do Sudeste (Grande São Paulo, Rio de Janeiro, Campinas, Belo Horizonte e São José dos Campos) participavam com $49 \%$ dos pesquisadores, $56 \%$ dos doutores, $50 \%$ das publicações em periódicos nacionais e $64 \%$ em periódicos internacionais. Ainda segundo os autores, as regiōes do País podem ser divididas de acordo com suas possibilidades de desenvolvimento de produtos e processos intensivos em conhecimento técnico-científico e informação, de forma que se teria a "Região Dinâmica”, que inclui metrópoles e cidades médias das regiōes Sudeste e Sul; a "Região Atrasada”, que abarcaria grandes cidades do Nordeste caracterizadas por terem desvantagens em relação às cidades do Centro-Sul para atrair e desenvolver empresas intensivas em conhecimento; e por fim a "Região Vazia", especializadas na produção de commodities.

Ainda pesquisando a situação brasileira, Silva e Simões (2004) analisam a localização espacial das atividades científicas e industriais do País, por meio de análise de cluster, como forma de verificar a existência ou não de interações entre a atividade industrial e o surgimento de "oportunidades tecnológicas" (Klevorick et al., 1995). Utilizando como dados o número de artigos científicos entre os quais ao menos um autor declarou endereço no país, e o número de empregados nos setores industriais, por município e classe da Classificação Nacional de Atividade Econômica - CNAE (estes últimos obtidos na RAIS 2000, e usados como proxy para a escala industrial), os autores observaram, entre outros pontos, que a concentração da atividade industrial e científica na Região Sudeste, em especial no Estado de São Paulo, se evidencia na observação da existência de maiores oportunidades tecnológicas nessa região.

Diante destas tentativas de entender o fenômeno da produção de inovações com valor econômico sob um enfoque espacial, no Brasil e no mundo, e da dificuldade em operar os chamados microdados da PINTEC, o presente texto propõe uma metodologia exploratória de regionalização dos dados primários divulgados nesta pesquisa, que tem como principal resultado, os gastos em P\&D do setor produtivo divididos conforme o ramo de atividade. A hipótese a ser testada é a de que - assim como as diversas variáveis que expressam o nível de renda, emprego e desenvolvimento socioeconômico no Brasil - as atividades de cunho inovativo mais evidentes são espacialmente concentradas e revelam a heterogênea realidade nacional em termos de desenvolvimento regional; 
e mais, a hipótese de que os gastos em P\&D são setorialmente condicionados mesmo dentro das regiōes privilegiadas. Estas hipóteses são fundamentadas em fenômenos típicos ao desenvolvimento tardio e desigual da periferia capitalista e a corroboração destas guiará, entre outras iniciativas, a formulação de estratégias específicas para o caso brasileiro que visem aliviar restrições diversas tais como, por exemplo, a do balanço de pagamentos tecnológico (deficitário) do País (FAPESP, 2002).

\section{Informações acerca da atividade inovativa no Brasil: problemas e potencialidades}

Os dados da PINTEC são os primeiros realizados no Brasil que trazem resultados válidos para todo o universo da indústria residente no País (a partir de dados amostrais) ${ }^{2}$ e são perfeitamente comparáveis a pesquisas realizadas em outros países devido à adoção de metodologia amplamente empregada ao redor do mundo. ${ }^{3}$ O período de referência da pesquisa abrange os anos de 1998, 1999 e 2000, porém os dados quantitativos referem-se apenas ao último exercício, ou seja, o ano de 2000. Das diversas variáveis levantadas na PINTEC, a que será trabalhada aqui é a que se refere aos gastos diretos com a atividade de P\&D realizada no interior das firmas de cada setor industrial (com exceção do setor de reciclagem, ver Quadro 2). Como atividade interna de P\&D entende-se o

conjunto de atividades inovativas que compreende o trabalho criativo, empreendido de forma sistemática, com o objetivo de aumentar o acervo de conhecimentos e o uso destes conhecimentos para desenvolver inovações tecnológicas. Engloba o desenho, a construção e o teste de protótipos e de instalações-piloto bem como o desenvolvimento de software, quando este resulta em avanço tecnológico ou científico (IBGE, 2002).

\footnotetext{
2 A amostra conta com mais de 70 mil empresas que atuam no território brasileiro e empregam cada uma mais de dez funcionários.

3 "A referência conceitual e metodológica da PINTEC é o Oslo manual: proposed guidelines for collecting and interpreting technological innovation data 1997. Mais especificamente, a pesquisa se inspirou na experiência do modelo harmonizado proposto pelo EUROSTAT, a terceira versão da Community Innovation Survey, da qual participam os 15 países membros da comunidade européia" (IBGE, 2002).
} 
A escolha desta variável como principal indicador da atividade inovativa do setor produtivo repousa no fato de que as empresas altamente dinâmicas que produzem bens com alto conteúdo tecnológico, e por isso valorizam mais o fator conhecimento, têm como rotina mais importante, embora não exclusiva, nesse sentido, o esforço institucionalizado de P\&D. Esta colocação segue no sentido de confirmar a hipótese básica aqui apresentada de que os setores intensivos em tecnologia tendem a se concentrar mais facilmente no espaço, tirando maior proveito das economias de aglomeração (muito nítidas nos sistemas de inovação urbanos), pois, como é possível destacar da literatura pertinente, alguns fatores, mais que outros, condicionam a localização destas: a presença de diferentes insumos oriundos de diferentes tipos de conhecimento; a reunião de instituições que produzem conhecimento (ciência básica e ciência aplicada); concentração de mão-de-obra qualificada detentora de expressivo conhecimento tácito (importante frisar: localmente determinado), etc. (Audretsch \& Feldman, 1996; Ki, 2001; Frenkel, 2001).

Assim, não obstante haja grande comparabilidade entre os dados de gastos nacionais em P\&D e os dados internacionais, o presente trabalho representa um avanço, ao passo que permite uma comparação pormenorizada entre setores regionalmente/internamente distribuídos no Brasil. Tem-se, então, a oportunidade de melhor entender a dinâmica da localização e acumulação guiada pela economia do conhecimento ao nível da indústria e ao nível local, minimizando desvantagens comuns relacionadas aos dados sobre patentes e artigos, freqüentemente utilizados na literatura, tais como as de que nem toda inovação é patenteável, nem toda inovação é patenteada, nem todo artigo contribui com conhecimentos diretamente aplicáveis à produção, e a de que existem diferentes propensões intersetoriais a patentear.

Ademais, uma consideração adicional importante é a de que a ausência de um plano de divulgação de informaçóes dos dados da PINTEC torna ainda mais pertinente a realização deste trabalho frente à incerteza da disponibilidade de dados regionalizados.

O nível de agregação utilizado neste trabalho é arbitrariamente elevado, tanto no que diz respeito às atividades (dois dígitos da classificação CNAE) quanto no que respeita à regionalização (em termos de unidades federativas - UF). A despeito disso, o método é perfeitamente aplicável a menores níveis de agregação setorial e a menores unidades de localização e de planejamento espacial. 
Anteriormente à divulgação da PINTEC os dados existentes acerca da produção nacional de tecnologia por parte do setor privado - utilizados como referência pelo Ministério da Ciência e Tecnologia - MCT, eram fornecidos pela Associação Nacional de Pesquisa, Desenvolvimento e Engenharia das Empresas Inovadoras - ANPEI. ${ }^{4}$ Essa série de informaçōes, disponível desde 1993, sofre de várias limitações que dificultam inferências mais rigorosas, a saber: i) as informações são coletadas a partir de questionários que apresentam um baixo índice de respostas; ii) o grupo de empresas respondentes varia a cada ano; iii) por estes motivos os dados não são passíveis de comparação temporal entre si. A fim de que se dirimissem tais problemas foram buscadas alternativas como, por exemplo, a expansão dos resultados a um universo amostral maior de empresas (para detalhes ver o sítio do MCT), o que, por seu turno, não se mostrou realmente satisfatório por não representar adequadamente os esforços empresariais no que se refere à criação de conhecimento interno às unidades privadas.

Além disso, e assim como a PINTEC, os dados trabalhados pela ANPEI são setoriais e não trazem informações de caráter territorial, compartilhando, dessa forma, as limitações apontadas na primeira.

Outras iniciativas, mais atentas à regionalização (em parte por serem desagregadas), podem ser lembradas, como a pesquisa realizada pela Fundação de Amparo à Pesquisa do Estado de São Paulo - FAPESP, que contextualizou a referida unidade federativa no panorama internacional, atualmente em expansão, da ciência e da tecnologia, bem como localizou a contribuição paulista na melhora dos indicadores nacionais. Além desta, foram realizados trabalhos que também se preocuparam com a situação de outros estados brasileiros, ainda que de forma indireta e com uma metodologia específica, como é o caso em Britto (1999).

Embora não existam referências territoriais (no que tange às UF) nos resultados divulgados pela PINTEC, o questionário da pesquisa revela algumas informações referentes ao aspecto espacial da produção de conhecimentos por parte das firmas; as mais pertinentes ao estudo aqui desenvolvido são: a pergunta 36 que pede a localização (em nível estadual apenas) do Departamento de P\&D da empresa ou unidade formal equivalente onde se concentram tais atividades e a pergunta 132 que indaga, no caso de registro de patente dentro do

\footnotetext{
4 Esta serviu inclusive como referência para a construção do plano amostral da própria PINTEC.
} 
período pesquisado, onde ela foi solicitada (no Brasil, no exterior ou em ambos). Estas questôes nos permitem intuir sobre a possibilidade de uma configuração espacial da atividade inovativa brasileira distinta da configuração espacial da atividade produtiva, uma vez que, não necessariamente a localização dos esforços de P\&D coincide com a localização da planta produtiva da firma em questão. Em outras palavras, a dinâmica de produção e acumulação de conhecimentos e de inovações tecnológicas não precisa ser a mesma, em termos locacionais, da dinâmica da transformação e produção de mercadorias, ainda que a firma seja a mesma. A segunda pergunta destacada do questionário nos permite evidenciar as limitações do uso da variável de produção científico-tecnológica de patentes, que aqui será usada como calibrador dos dados estimados, dentre as quais a mais notável é a de que ela reflete o (ainda dominante) aspecto da cultura brasileira de não registrar os seus achados (FAPESP, 2002; Alem, 2003).

Como podemos deduzir da Introdução, a literatura até agora realizada, no Brasil e no exterior, tentou se aproveitar de diversas formas de mensuração para constatar regularidades e relações entre a produção de conhecimentos passíveis de utilização industrial e a localização de setores específicos dentro de um dado território.

Vale salientar que em alguns destes estudos as informações/variáveis usadas pelos autores têm uma clara e não-ambígua associação territorial que lhes permitem melhores inferências acerca do fenômeno econômico geograficamente localizado submetido à análise. Os efeitos de transbordamento na produção científica interinstitucional, por exemplo, torna-se mais evidente e as conclusóes em torno da idéia de concentração (inovativa e produtiva) mais seguras. São exatamente estes elementos que a metodologia descrita nas próximas seções persegue.

\section{Fonte de informações}

A tentativa de localização das atividades de alta tecnologia no Brasil passa por algumas limitações, uma vez que não existem dados das atividades econômicas em nível setorial distribuídos regionalmente. Ou seja, não há um retrato da distribuição dos pólos tecnológicos no espaço. Uma das alternativas propostas para efetuar este trabalho é relacionar os dados existentes de pessoas ocupadas da Relação Anual de Informações Sociais - RAIS e de dispêndios em ativi- 
dades, internas à firma, de P\&D contidos na PINTEC. Este procedimento procura obter a participação percentual do trabalho qualificado (e, conseqüentemente, dos gastos em P\&D) para cada setor e unidade da federação.

Os dados de ocupação selecionados basearam-se nos três primeiros dígitos do Código Brasileiro de Ocupação - CBO e foram obtidos da RAIS 2000, com exceção dos dados referentes à fabricação de coque, refino de petróleo e elaboração de combustíveis nucleares para os estados da Bahia e do Rio Grande do Norte, que foram referentes a 1999.5

Os grupos de emprego que foram escolhidos são os que, teoricamente, têm potencial de se dedicarem ao desenvolvimento de ciência e tecnologia, sendo constituídos por trabalhadores de nível médio - técnicos - e de nível superior, ou seja, mão-de-obra qualificada, insumo básico para a produção de inovaçôes tecnológicas (Quadro 1). Tal procedimento, de usar esta variável como proxy, pode ser visto em outros trabalhos - como, por exemplo, em Britto (1999) e em Silva e Simões (2004).

As ocupações relacionadas às categorias de professores de ensino superior foram desconsideradas da análise uma vez constatada a pequena significância dos valores obtidos por tais categorias nos subsetores destacados. ${ }^{6}$

Os dados de dispêndios em P\&D em atividades internas às firmas foram retirados da PINTEC 2000 e correspondem às atividades da indústria extrativa e de transformação, consideradas as atividades que potencialmente investem em pesquisa e desenvolvimento. Os setores econômicos têm sua divisão feita de acordo com a CNAE - Classificação Nacional de Atividades Econômicas (IBGE) a dois dígitos (Quadro 2). O subsetor "extrativista", de acordo com a PINTEC, engloba as atividades representadas pelos códigos de 10 a 14. Assim sendo, no Quadro 2 e nas tabelas subseqüentes que se referem ao conjunto de

\footnotetext{
5 Não foram utilizados os dados de 2000 nesse caso porque os mesmos foram considerados duvidosos, ao compará-los com os dados de Minas Gerais e de São Paulo. Segundo a RAIS, em 2000, o número de pessoas ocupadas no setor referido na Bahia e no Rio Grande do Norte foi de 1.291 e 294, respectivamente. Valores muito superiores aos de São Paulo e de Minas Gerais, que tiveram 331 e 139 pessoas ocupadas, respectivamente. A utilização da variável "massa salarial", também obtida da RAIS, reforça este questionamento. A massa salarial (em Reais) neste setor correspondia a 44.953,48 e 10.017,59 para os estados da Bahia e do Rio Grande do Norte, respectivamente. São Paulo e Minas Gerais obtiveram 3.026,05 e 1.674,54, respectivamente.

6 No entanto, os subsetores "edição, impressão e reprodução de gravações" e "fabricação e montagem de veículos automotores, reboques e carrocerias" obtiveram relevância nas categorias de "professores de ciências econômicas, administração e contábeis de ensino superior" e "professores de engenharia e arquitetura de ensino superior", respectivamente. Apesar disto, tais dados também foram suprimidos já que apresentavam-se concentrados em uma única unidade da federação (no primeiro, Paraná, e no segundo, São Paulo) e, por isto, poderiam enviesar os resultados.
} 


\section{QUADRO 1 \\ Ocupações selecionadas da RAIS}

Químicos

Físicos

Químicos e físicos e trabalhos assemelhados não classificados sob outras epígrafes

Engenheiros agrônomos, florestais e de pesca

Engenheiros civis e arquitetos

Engenheiros de operação e desenhistas industriais

Engenheiros eletricistas e engenheiros eletrônicos

Engenheiros mecânicos

Engenheiros químicos

Engenheiros metalúrgicos

Engenheiros de minas e geólogos

Engenheiros de organização e métodos

Engenheiros arquitetos e trabalhos assemelhados não classificados sob outras epígrafes

Técnicos de contabilidade, estatística e economia doméstica

Técnicos de biologia, agronomia e trabalhos assemelhados

Técnicos de mineração, metalurgia e geologia

Técnicos de edifagrimensura, estradas e saneamento e trabalhos assemelhados

Técnicos de eletricidade, eletrônica e telecomunicações

Técnicos de mecânica

Técnicos de química e trabalhadores assemelhados

Técnicos têxteis

Desenhistas técnicos

Técnicos, desenhistas e trabalhos assemelhados não classificados sob outra epígrafe

Biologistas e trabalhos assemelhados

Bacteriologistas, farmacologistas e trabalhos assemelhados

Engenheiros agrônomos, florestais e de pesca

Médicos

Enfermeiros

Cirurgiões-dentistas

Médicos-veterinários e trabalhos assemelhados

Farmacêuticos

Nutricionistas e trabalhos assemelhados

Ortoptistas e ópticos

Médicos, cirurgiões-dentistas, médicos veterinários, enfermeiros e trabalhos assemelhados não classificados sob outra epígrafe

Estatísticos

Matemáticos e atuários

Analistas de sistemas

Programadores de computador

Fonte: elaboração própria a partir de informações da RAIS 2000. 
QUADRO 2

Setores extraídos da PINTEC

(10) Indústrias extrativas

(15) Fabricação de produtos alimentícios e bebidas

(16) Fabricação de produtos do fumo

(17) Fabricação de produtos têxteis

(18) Confecção de artigos do vestuário e acessórios

(19) Preparação de couros e fabricação de artefatos de couro, artigos de viagem e calçados

(20) Fabricação de produtos de madeira

(21) Fabricação de produtos de celulose, papel e produtos de papel

(22) Edição, impressão e reprodução de gravações

(23) Fabricação de coque, refino de petróleo, elaboração de combustíveis nucleares e produção de álcool

(24) Fabricação de produtos químicos

(25) Fabricação de artigos de borracha e de material plástico

(26) Fabricação de produtos de minerais não-metálicos

(27) Metalurgia básica

(28) Fabricação de produtos de metal - exclusive máquinas e equipamentos

(29) Fabricação de máquinas e equipamentos

(30) Fabricação de máquinas para escritório e equipamentos de informática

(31) Fabricação de máquinas, aparelhos e materiais elétricos

(32) Fabricação de material eletrônico e de aparelhos e equipamentos de comunicações

(33) Fabricação de equipamentos de instrumentação médico-hospitalares, instrumentos de precisão e ópticos, equipamentos para automação industrial, cronômetros e relógios

(34) Fabricação e montagem de veículos automotores, reboques e carrocerias

(35) Fabricação de outros equipamentos de transporte

(36) Fabricação de móveis e indústrias diversas.

Fonte: elaboração própria a partir de informações da PINTEC 2000.

Nota: a disposição dos setores segue a CNAE do IBGE, considerando que a atividade extrativista, conforme a PINTEC, engloba os códigos de 10 a 14.

atividades que compõe a indústria nacional, o subsetor "extrativista" será relacionado ao código 10, enquanto os demais subsetores serão designados pelos seus respectivos códigos na CNAE.

É importante destacar que o subsetor "reciclagem" da indústria de transformação foi excluído da análise deste trabalho devido à ausência de informações de tal subgrupo nos dados da PINTEC. 
Os dados percentuais de patentes para as unidades federativas foram obtidos do Instituto Nacional da Propriedade Intelectual - INPI e referem-se aos registros de pessoas jurídicas, no ano de 2000.

\section{Ajuste biproporcional entre os resíduos}

Um procedimento direto, e correto como ponto de partida, seria tomarmos os gastos setoriais globais em $\mathrm{P} \& \mathrm{D}$ e os distribuirmos proporcionalmente à estrutura ocupacional teoricamente vinculada às atividades de $\mathrm{P} \& \mathrm{D}$ setorialmente em cada $\mathrm{UF}^{7}$ (Tabelas 1 e 2), gerando uma matriz de gastos regionais $\mathrm{G}$, bastante inicial e introdutória do investimento inovativo. Esta primeira aproximação já nos daria uma visão, em grande angular, da distribuição espacial da inovação no País.

Contudo, este procedimento pode mascarar dois movimentos importantes e enviesar a estimativa em nível regional, a saber: i) como já foi dito, apesar dos dados de ocupação da classificação CNAE serem utilizados por diversos autores (como Britto, 1999; Silva \& Simões, 2004, entre outros) com intuito de estimar pessoal ocupado em atividade inovativa, a RAIS não menciona vinculação específica a laboratórios de $\mathrm{P} \& D$ e evidentemente esta parcela varia muito inter e intra-setorialmente, superestimando seus valores; e ii) setores intensivos em capital tendem a ser sub-representados se tomamos apenas o pessoal ocupado como parâmetro de distribuição regional dos gastos em inovação.

Visando mitigar estes problemas, propóe-se aqui uma metodologia que, após este arranjo inicial que regionaliza a distribuição de gastos em P\&D por intermédio da estrutura ocupacional, procura balizar os mesmos por um critério objetivo diretamente vinculado à produção de tecnologia no País, vale dizer, o registro de patentes de pessoas jurídicas registradas no INPI, tomadas em nível regional ${ }^{8}$ (Tabela 3). No entanto, há de se considerar as limitaçôes destes dados, já explicitadas anteriormente.

\footnotetext{
7 Foi utilizada a classificação CNAE-IBGE para atividades de nível superior e técnico vinculadas ao setor produtivo, tais como engenheiros, físicos, químicos, laboratoristas, etc. Ver Britto (1999) e Silva \& Simões (2004) que utilizaram classificações análogas para mensurar atividades assemelhadas.

8 Aqui iremos usar Unidades da Federação, mas a metodologia nos permite trabalhar com níveis de desagregação menores, chegando mesmo aos municípios. Evidentemente, o grau de acuidade das estimativas é proporcional à sua agregação.
} 
TABELA 1

Distribuição de gastos em P\&D da PINTEC por setores (em R\$ e em \%)

\begin{tabular}{|c|c|c|}
\hline \multirow[b]{2}{*}{ Setores } & \multicolumn{2}{|c|}{ PINTEC } \\
\hline & $R \$ 1.000,00$ & $\%$ \\
\hline 10 & $29.094,00$ & 0,78 \\
\hline 15 & $227.680,00$ & 6,09 \\
\hline 16 & $23.474,00$ & 0,63 \\
\hline 17 & $45.223,00$ & 1,21 \\
\hline 18 & $22.063,00$ & 0,59 \\
\hline 19 & $33.976,00$ & 0,91 \\
\hline 20 & $11.974,00$ & 0,32 \\
\hline 21 & $73.591,00$ & 1,97 \\
\hline 22 & $10.362,00$ & 0,28 \\
\hline 23 & $446.064,00$ & 11,92 \\
\hline 24 & $527.072,00$ & 14,09 \\
\hline 25 & $91.227,00$ & 2,44 \\
\hline 26 & $51.411,00$ & 1,37 \\
\hline 27 & $144.842,00$ & 3,87 \\
\hline 28 & $60.585,00$ & 1,62 \\
\hline 29 & $341.960,00$ & 9,14 \\
\hline 30 & $109.060,00$ & 2,91 \\
\hline 31 & $260.631,00$ & 6,97 \\
\hline 32 & $387.155,00$ & 10,35 \\
\hline 33 & $70.292,00$ & 1,88 \\
\hline 34 & $472.237,00$ & 12,62 \\
\hline 35 & $260.270,00$ & 6,96 \\
\hline 36 & $41.329,00$ & 1,10 \\
\hline Total & $3.741 .572,00$ & 100,00 \\
\hline
\end{tabular}

Fonte: elaboração própria a partir de dados da PINTEC 2000. 


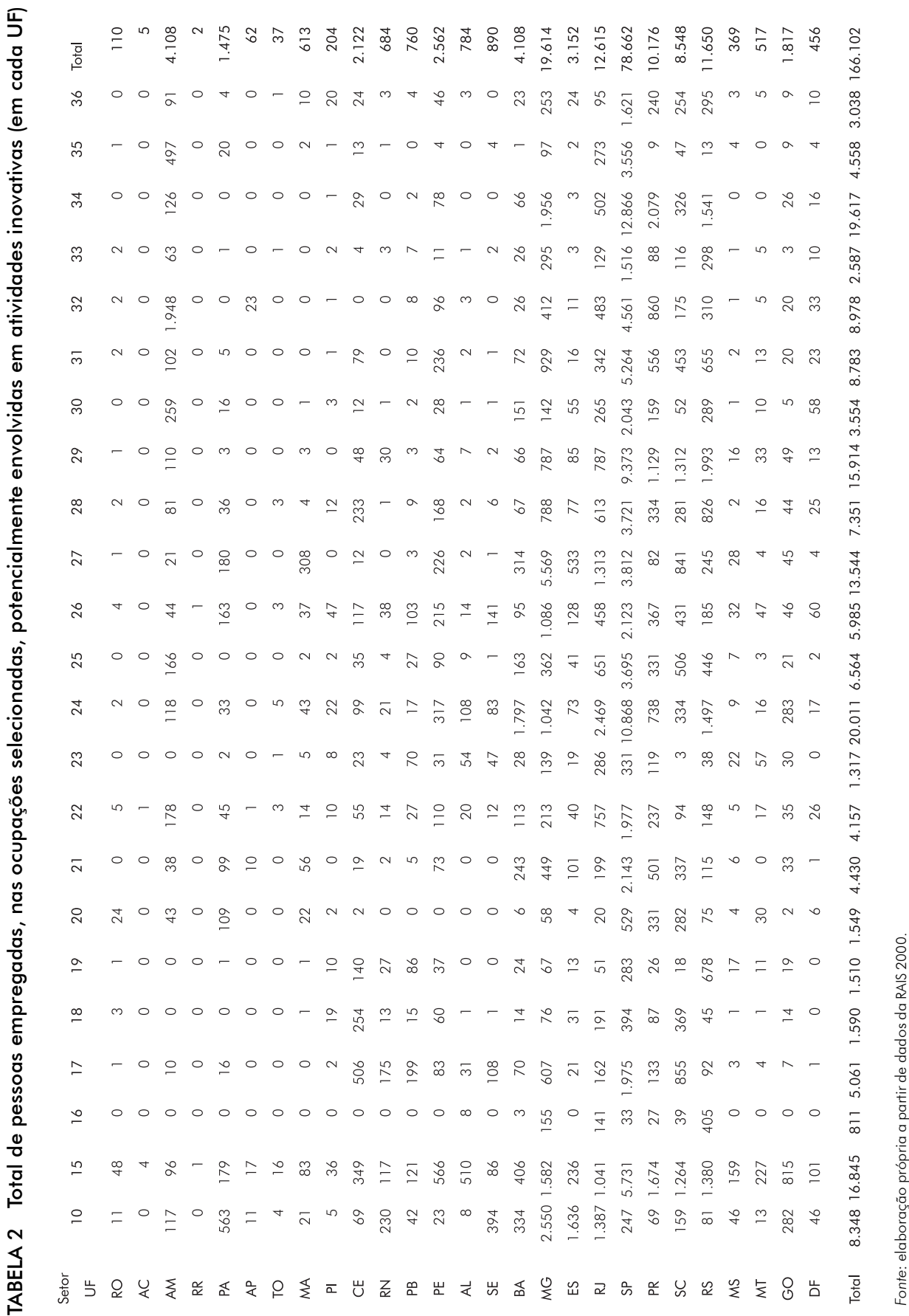


TABELA 3

Patentes de pessoas jurídicas por estados e DF (\%)

\begin{tabular}{|c|c|}
\hline Unidades Federativas & Patentes (\%) \\
\hline Rondônia & 0,00 \\
\hline Acre & 0,00 \\
\hline Amazonas & 0,35 \\
\hline Roraima & 0,00 \\
\hline Pará & 0,07 \\
\hline Amapá & 0,00 \\
\hline Tocantins & 0,07 \\
\hline Maranhão & 0,14 \\
\hline Piauí & 0,14 \\
\hline Ceará & 0,42 \\
\hline Rio Grande do Norte & 0,00 \\
\hline Paraíba & 0,00 \\
\hline Pernambuco & 0,49 \\
\hline Alagoas & 0,00 \\
\hline Sergipe & 0,00 \\
\hline Bahia & 0,21 \\
\hline Minas Gerais & 6,16 \\
\hline Espírito Santo & 0,49 \\
\hline Rio de Janeiro & 7,49 \\
\hline São Paulo & 57,00 \\
\hline Paraná & 6,30 \\
\hline Santa Catarina & 6,86 \\
\hline Rio Grande do Sul & 11,62 \\
\hline Mato Grosso do Sul & 0,00 \\
\hline Mato Grosso & 0,14 \\
\hline Goiás & 0,21 \\
\hline Distrito Federal & 1,82 \\
\hline Total & 100,00 \\
\hline
\end{tabular}

Fonte: elaboração própria a partir de dados da PINTEC 2000.

Chamando de $\mathrm{R}$ a matriz com a estrutura percentual de gastos regionais em $\mathrm{P} \& D$, calculada a partir de $\mathbf{G} ; \mathbf{v}_{\mathbf{j}} \mathbf{o}$ vetor coluna somatório dos percentuais regionais a partir da matriz $\mathbf{R}$; e $\mathbf{p}_{\mathrm{i}}$ o vetor linha de gastos setoriais percentuais com $\mathrm{P} \& \mathrm{D}$ fornecidos pela PINTEC; a essência do ajuste a ser aqui realizado consiste em 
estabelecer um algoritmo que progressivamente iguale a distribuição proporcional de $\mathbf{R}$ em $t-1$ à distribuição proporcional de $\mathbf{R}$ em $t+1-\operatorname{sendo~} t$ uma etapa de estimação algorítmica - tal que em $t=n$ seja alcançada uma matriz $\mathbf{R}^{*}$, cuja estrutura interna respeite a integridade da distribuição marginal $\mathbf{p}_{\mathrm{i}}{ }^{9}$ e a alteração da distribuição marginal da coluna $\mathbf{r}_{\mathbf{j}}$ experimente uma convergência marginal, tal como proposto em Bacharach (1970). ${ }^{10}$

O método para solução deste problema é o chamado ajuste biproporcional entre os resíduos (Biproportional Residual Adjustment). Este é um processo iterativo, que começa por ajustar proporcionalmente as linhas da matriz $\mathbf{R}$ a uma nova marginal, $\mathbf{m}_{\mathbf{j}}$ - vetor coluna de percentuais de registros de patentes. Como este primeiro procedimento implica necessariamente o desajuste das colunas, a segunda etapa de estimação do algoritmo é o reajuste das colunas, seguido de um novo ajuste de linhas et passim.

Dado que

$$
E_{s t r}^{t+1}{ }_{i j}^{1} E_{s t r}^{t} \quad \text { onde } \mathrm{t}=0
$$

Torna-se necessário retirar a diferença entre o total estimado e o total observado pela PINTEC, no caso de ajuste das colunas, ou pelo registro de patentes, no caso de ajuste das linhas, de modo que

$$
E s t r_{i j}^{t}=r_{i j}-[\underbrace{\left(\sum_{i} r_{i j}^{t+1}-m_{j}\right)}_{\text {diferença regional }} a_{i}]-[\underbrace{\left(\sum_{j} r_{i j}^{t+1}-p_{i}\right)}_{\text {diferença setorial }} b_{i}]
$$

\footnotetext{
9 Pois a informação do gasto setorial em P\&D fornecido pela PINTEC é tomado como nosso balizador por excelência, sendo os ajustes do algoritmo "descarregados" na estrutura ocupacional.

10 Este procedimento foi originalmente proposto e é freqüentemente utilizado em ajustes e previsões de matrizes de insumoproduto - RAS Method - e representações de processos markovianos. Fora análises de insumo-produto, Simões (1989) utilizou esta técnica para estimar informações fechadas dos censos econômicos para uso em análise regional; Wajnman (1995) fez uso desta técnica para isolar efeitos temporais analisando ciclo de vida e ocupação no Brasil, dentre outros.
} 
onde

Est $r_{i j}^{t}=$ valor estimado de $\mathrm{r}_{\mathrm{ij}}$ etapa $\mathrm{t}$ de estimação

$\sum_{i} r_{i j}^{t+1}=$ gastos em P \&D em todos os setores da região $\mathrm{j}$

$\sum_{j} r_{i j}^{t+1}=$ gastos em P \&D do setor i de todas as regióes

$a_{i}=\frac{g_{i j}^{t-1}}{\sum i g_{i j}^{t-1}}$

$b_{i}=\frac{g_{i j}^{t-1}}{\sum j g_{i j}^{t-1}}$

sendo $\mathbf{a}_{\mathrm{i}}$ e $\mathbf{b}_{\mathrm{i}}=$ participação relativa dos gastos setoriais/regionais em P\&D estimados na etapa anterior da estimação.

Os ajustes sucessivos de valores de $\mathbf{r}_{\mathrm{ij}}$ são repetidos até a convergência marginal aos valores predeterminados (Bacharach, 1970:21-22). A propriedade básica do ajuste biproporcional é que a diferença conjunta dos resíduos, no somatório passo a passo de linhas e colunas, após t etapas de estimação é sempre maior que após $t+1$, fazendo com que haja convergência após $t+n$ estimativas (Bacharach, 1970). ${ }^{11}$ A etapa final do ajuste é mostrada na Tabela 4.

\section{Interpretação preliminar dos resultados}

A metodologia proposta neste artigo, ainda que exploratória, permite uma série grande de constatações imediatas a partir da análise dos resultados obtidos no ajuste final (Tabela 4). O exercício de regionalização dos dados de gastos privados em P\&D presentes na PINTEC permite a percepção clara das tendências distributivas das atividades inovativas no País, e por conseguinte, do maior potencial de geração de riquezas do Brasil: a capacidade de usar o "conhecimento" nas práticas industriais.

Segundo a PINTEC, 58\% do montante gasto em P\&D no Brasil é realizado apenas por firmas selecionadas entre cinco setores industriais de um total de 23

${ }^{11}$ O procedimento padrão na literatura é que se defina ex-ante um limite numérico, a fim de se reduzir o tempo de 


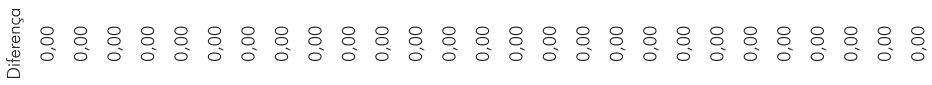

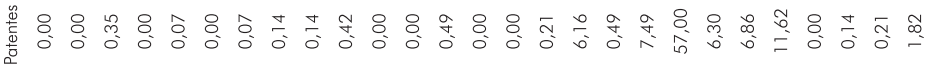

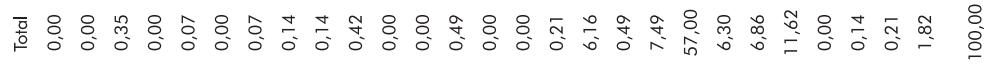

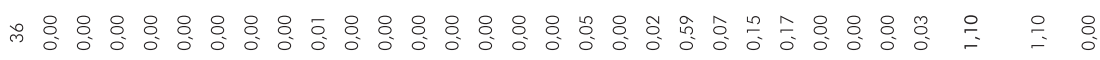
m : : :

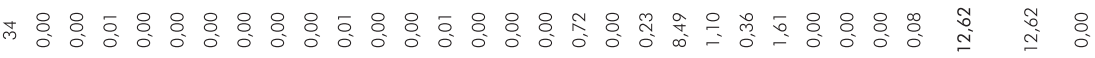
m 잉

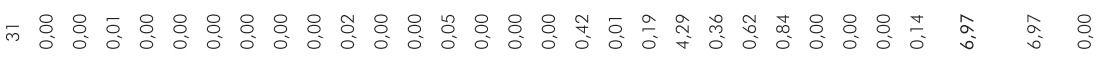

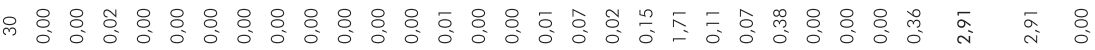
융 $:$ 串

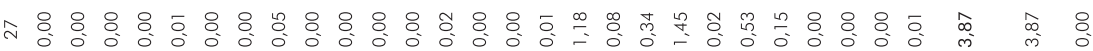

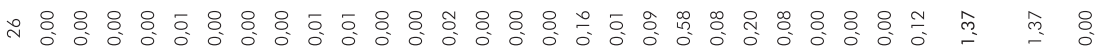
ผ

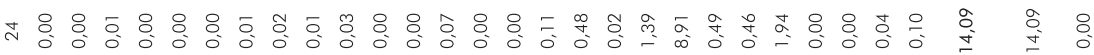
영

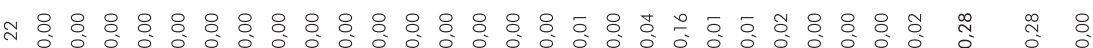

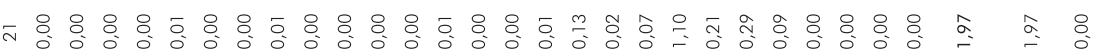

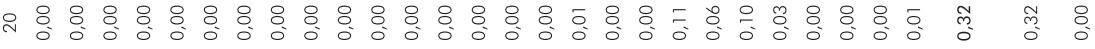
영영 $:$

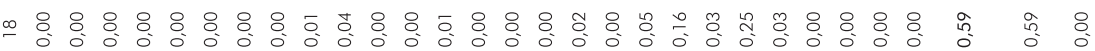
=

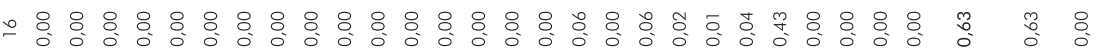

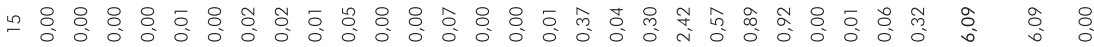

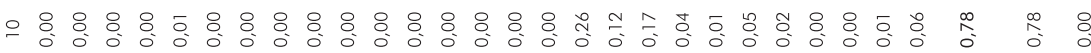

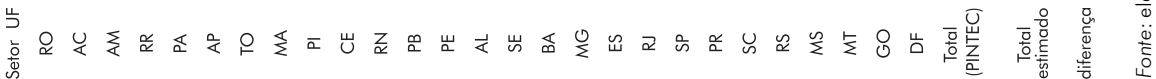


considerados, a saber: químicos com $14,09 \%$; veículos com 12,62\%; coque com $11,92 \%$; e eletrônicos e máquinas e equipamentos com 10,35\% e 9,14\% respectivamente. Essa concentração, ainda que considerável, é justificada (ou justificase) pelo razoavelmente alto nível tecnológico destas cadeias produtivas (Tabela 1).

Continuando a avaliação em termos de concentração setorial da iniciativa inovativa, nota-se também a surpreendente participação que os setores de químicos e veículos localizados só no Estado de São Paulo têm no total de gastos do País. Cerca de 8,91\% dos gastos em P\&D na indústria brasileira são oriundos do setor químico do Estado de São Paulo e 8,49\% do total do P\&D privado nacional é feito nas empresas paulistas de veículos (Tabela 4). Estas parcelas do total de gastos representam o $6^{\circ}$ e o $7^{\circ}$ lugares, respectivamente, entre os dados nacionais para os setores. A produção estimada de inovações do setor de máquinas, aparelhos e materiais elétricos, por exemplo, em todo o Brasil é inferior (e bastante inferior) à produção de inovações dos referidos setores na referida UF.

A desigualdade a favor de São Paulo é ainda mais significativa que isto, pois dos 23 setores considerados neste estudo, o Estado de São Paulo exerce a liderança em 19, concentrando $57 \%$ das inovações realizadas no País. Os quatro setores restantes são liderados pelo Rio Grande do Sul (fumo e couro), Minas Gerais (extrativismo) e Santa Catarina (vestuário e acessórios). Contudo, a participação destes quatro setores de notória baixa intensidade tecnológica no total de gastos em P\&D no Brasil é de somente 2,91\%. No que se refere à liderança do Estado de São Paulo na inovação dos setores, merece menção especial a concentração dos gastos em P\&D do setor de equipamentos de transporte; a quase totalidade das iniciativas (89,24\%) está localizada no estado, o maior índice de concentração setorial do País (Tabela 5).

Os dados revelaram que os estados da Região Sul têm um importante papel no quadro nacional de distribuição da capacidade de investimento e introdução de novidades no mercado. A união dos esforços inovativos do Rio Grande do Sul, de Santa Catarina e do Paraná supera em muito a junção dos gastos realizados no Sudeste excluindo São Paulo: 24,78\% contra 14,14\% respectivamente. Boa parte deste desempenho se deve ao Rio Grande do Sul, sobretudo quando nos referimos aos dados concernentes aos setores de produtos de metal e de instrumentação médico-hospitalar, respectivamente $18,59 \%$ e $18,12 \%$ do total setorial, e de máquinas e equipamentos $(18,74 \%$ do total setorial) onde 
产 m 出

牙 m

잉 沾

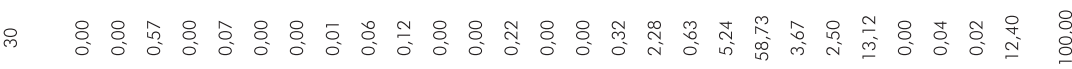

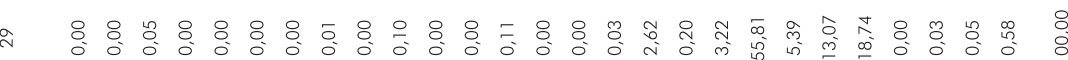

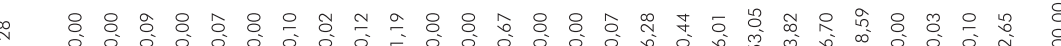

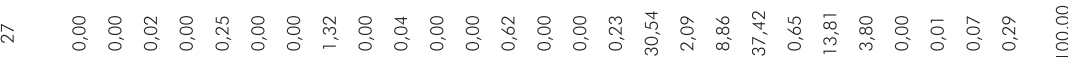

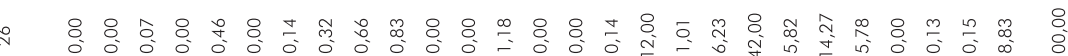

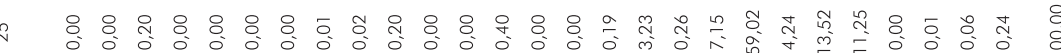

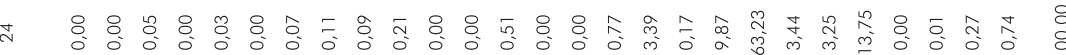

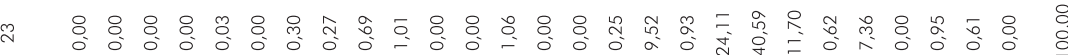

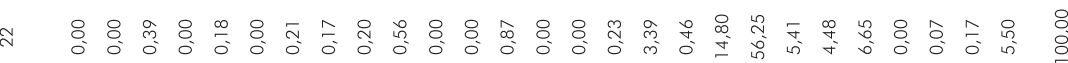

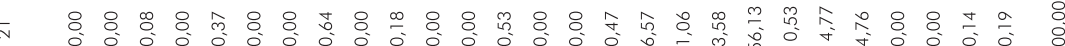

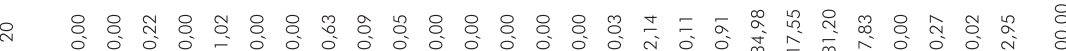
a œ

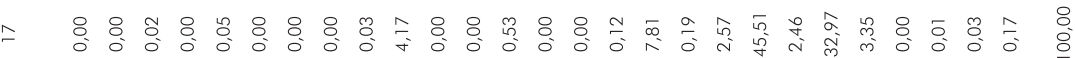

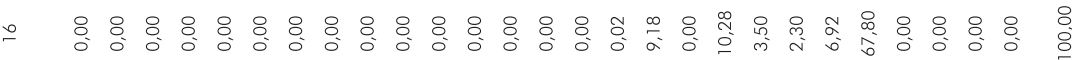

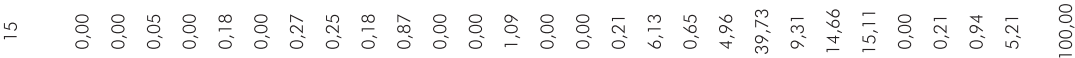

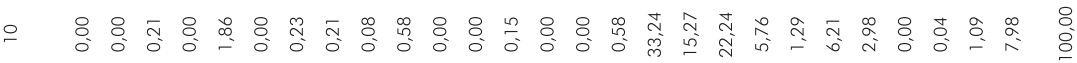

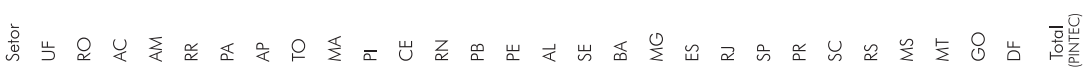


Santa Catarina também mantém uma participação relevante. Santa Catarina, por sua vez, tem maior importância relativa em setores mais "tradicionais" como o de têxteis, o de madeira e o de vestuário e acessórios, competindo, nos dois primeiros, muito de perto com São Paulo em termos de inovações setoriais (Tabela 5). Paraná tem como destaque a maior parcela das inovaçôes da Região Sul no setor de coque e petróleo $(59,45 \%)$ e é curiosamente mais eficiente que Minas Gerais no setor de veículos automotores empregando apenas 6\% mais trabalhadores especializados que Minas e produzindo aproximadamente 50\% mais inovações industriais no ramo (Tabelas 2 e 5 ).

Este resultado superior dos estados do Sul frente aos do Sudeste, exclusive São Paulo, também pode ser justificado pela forma como as unidades federativas dispõem seus gastos em atividades inovativas entre os diversos setores industriais. Os estados do Sul alocam maior parcela dos seus gastos em setores mais dinâmicos: o Rio Grande do Sul concentra seus gastos em P\&D no setor de químicos (16,66\%), veículos $(13,82 \%)$ e máquinas e equipamentos (14,73\%). Santa Catarina também concentra seus esforços no setor de máquinas e equipamentos, enquanto o Paraná prioriza os setores de refino de petróleo, eletrônicos e veículos. No Sudeste, no entanto, setores mais tradicionais são priorizados: Minas Gerais aloca 19,19\% dos seus gastos em P\&D no setor metalúrgico e o Espírito Santo disponibiliza 24,23\% e 16,53\% para os setores extrativista e metalúrgico, respectivamente (Tabela 6).

Minas Gerais que detém o terceiro PIB da Federação fica muito aquém das expectativas quando nos referimos às iniciativas inovativas. Como acabamos de ver, o setor de veículos do estado perde em eficiência inovativa para o Paraná e, em condições favoráveis à indústria mineira, também perde para o Rio Grande do Sul no mesmo critério, uma vez que possui $27 \%$ de empregados a mais, potencialmente voltados ao P\&D empresarial/corporativo, e o Rio Grande do Sul consegue inovar mais que o dobro no setor (Tabelas 2 e 5 ).

Além do mais, o único setor no qual o estado é líder tem participação ínfima no total de inovações do País: Minas Gerais, que tem um terço da capacidade inovativa no setor extrativista converte esta liderança para apenas $0,26 \%$ dos gastos em P\&D no País empregando $1,5 \%{ }^{12}$ do total de pessoas

\footnotetext{
12 Índice menor apenas que os dos setores de metalurgia, transportes e os de maior teor tecnológico dos estados mais importantes.
} 


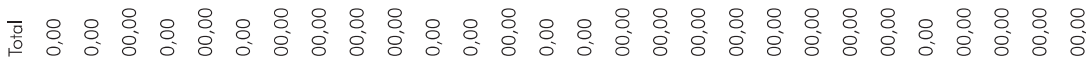
m

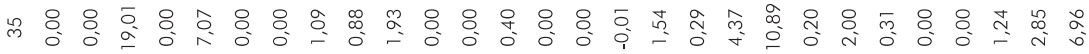
出 m

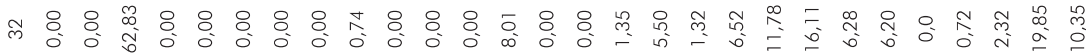
m 范

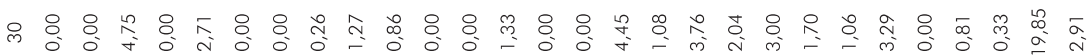

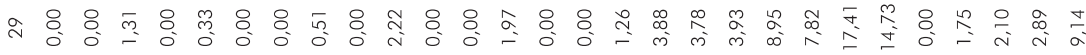

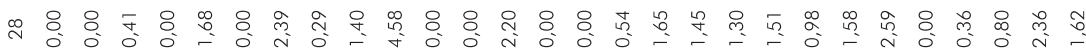
స

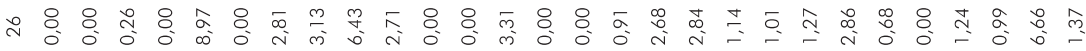

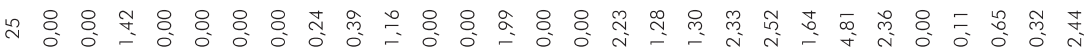

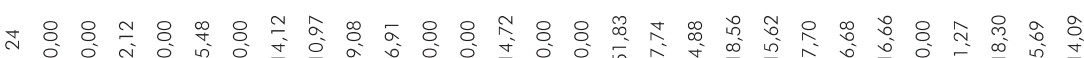

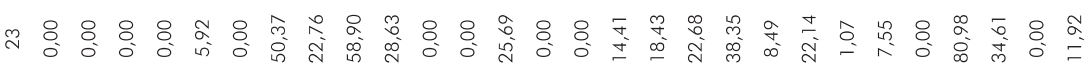
ส

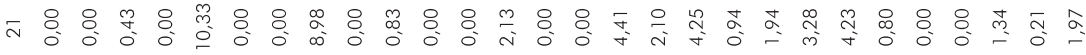

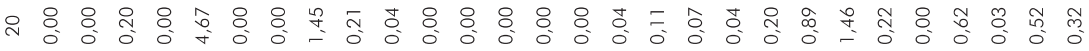

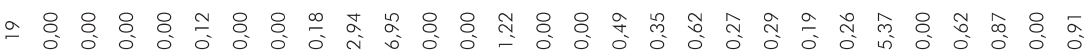

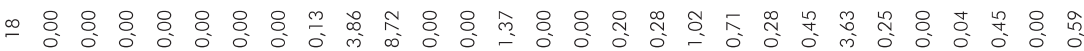
=

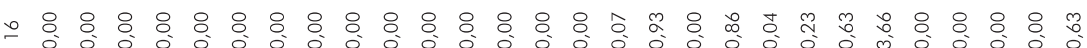

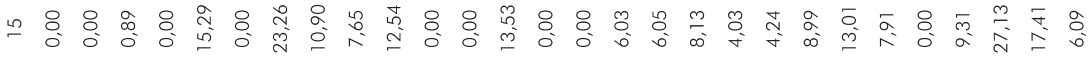
일

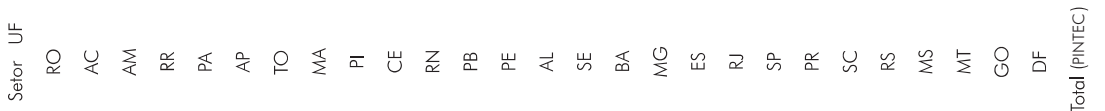


qualificadas na indústria - de transformação e extrativista - brasileira (cerca de $30 \%$ da mão-de-obra do setor extrativista). Quando este percentual é convertido para valor monetário ( $\mathrm{R} \$ 972.808 .720$ ) ele se revela mais de quatro vezes menor que o valor monetário alcançado pelos gastos em P\&D no setor metalúrgico ( $\mathrm{R}$ \$ 4.415.055.000), onde Minas Gerais ocupa a segunda posição inovativa dentro do setor. ${ }^{13}$

Nos demais setores, Minas Gerais exerce função indispensável ao ajudar a estabelecer a concentração das atividades inovativas na parte Centro-Sul do Brasil - concentração esta também evidenciada no trabalho de Albuquerque et al. (2002a) - especialmente no conjunto de estados que compõem o Sudeste e o Sul do País. No setor extrativista, por exemplo, $96,11 \%$ do total da atividade inovativa se encontra no Centro-Sul sendo que $76,51 \%$ do total feito no País estão na Região Sudeste. $\mathrm{O}$ setor de alimentos e bebidas, segundo os dados, tem quase $96,91 \%$ das suas atividades inovativas e a maior parte da mão-de-obra voltada para P\&D concentradas no Centro-Sul, isto no único setor que emprega pessoas potencialmente capazes de guiar P\&D em todos os estados da Federação e no Distrito Federal. Mais de $96 \%$ da produção de inovações no setor de máquinas, aparelhos e materiais elétricos estão no Sudeste e no Sul, a inclusão do CentroOeste, neste caso, muda muito pouco o quadro geral da indústria. Por fim, o setor moveleiro que tem algo em torno de $88 \%$ da capacidade inovativa instalada só na região que representa a junção de São Paulo com o Sul (Tabela 5).

Vale mencionar que dentro do Centro-Sul, Mato Grosso do Sul e Espírito Santo são estados que, cada qual dentro do seu contexto regional (ou seja, um no Centro-Oeste e outro no litoral Sudeste), estão totalmente à margem da distribuição da capacidade de tentar criar conhecimentos industrialmente úteis no País. O Mato Grosso do Sul apresentou participação nula no total de empreendimentos em P\&D desenvolvidos no Brasil, enquanto o Espírito Santo fica muito abaixo da média entre Minas Gerais e Rio de Janeiro, estando muito mais próximo dos estados de melhor desempenho no Nordeste que também estão excluídos do "circuito" inovativo brasileiro.

Para se ter idéia de tal exclusão cabe dizer que o setor de coque e refino de petróleo (que é o que apresenta melhor distribuição das inovações entre estados no Brasil) reserva somente $0,39 \%$ dos gastos nacionais para os estados do Nor-

\footnotetext{
${ }^{13} \mathrm{O}$ setor extrativista é um dos poucos em que São Paulo não é relevante.
} 
deste e apenas $0,04 \%$ para o Norte, ou melhor, para o Tocantins, onde, diga-se de passagem, a produtividade em termos tecnológicos da mão-de-obra qualificada no setor de alimentos e bebidas é mais de cinco vezes superior à produtividade de similares no Maranhão (Tabela 4).

No que se refere à Região Nordeste, destaca-se a predominância inovativa do Ceará e de Pernambuco em relação à Bahia. Enquanto, no ano 2000, o PIB do Ceará e de Pernambuco é de R \$ 20.799,548 milhōes e R \$ 29.126,796 milhōes, respectivamente, o PIB da Bahia apresenta um valor quase duas vezes maior, assumindo o montante de $\mathrm{R} \$ 48.197,174$ milhões (a preços de 2000). ${ }^{14}$ Contudo, este Estado participa com somente 0,21\% do total de inovações do País, o que representa quase a metade dos valores apresentados pelos estados do Ceará e de Pernambuco, 0,42\% e 0,49\% respectivamente, sendo que a Bahia, ao contrário dos outros dois estados, tem seus gastos em P\&D concentrados (em químicos).

O melhor desempenho percentual da Região Norte - insta ressaltar - se concentra no estado do Amazonas e se refere ao setor de eletrônicos e aparelhos de comunicações: o estado que é o segundo principal empregador do País, destina $62,83 \%$ dos gastos em P\&D para este setor, sendo responsável por 2,13\% das inovaçôes na referida indústria (Tabelas 5 e 6). Dentro do contexto da Região Norte como um todo, nesse sentido, Manaus pode ser considerada um enclave, com sua produção eletrônica de consumo baseada em incentivos fiscais (Diniz \& Gonçalves, 2000, 2001).

Um último dado mostra bem a situação da Região Norte frente às demais no País: do total de gastos em P\&D da PINTEC apenas 0,49\% foram realizados nesta região, o que corrobora a denominação de "Região Vazia" (com o CentroOeste) dada a ela por Diniz e Gonçalves (2000 e 2001), caracterizada principalmente pela presença das atividades agropecuária e mineral.

\section{Conclusão}

De uma maneira geral, pode-se dizer que a distribuição da atividade inovativa e, portanto, a distribuição dos setores mais intensivos em tecnologia no País, encontrada pelo exercício matemático realizado neste trabalho, apre-

\footnotetext{
14 A justificativa para a utilização dos dados referentes ao PIB dos estados no ano 2000 é a melhor comparabilidade entre estes e os dados da RAIS, PINTEC e INPI.
} 
sentou um padrão semelhante ao que se poderia esperar: maior importância dos estados das regióes Sul e Sudeste, tal como já apontado em trabalhos de Albuquerque et al. (2002a) e Diniz e Gonçalves (2000 e 2001).

É possível afirmar que os estados que se destacam, em termos do total gasto em P\&D, são os que contam, relativamente ao País como um todo, com uma infra-estrutura que permite o desenvolvimento mais intenso da atividade inovativa, o que talvez seja justificado, dentre outros fatores, pela presença de economias de aglomeração nesses estados (Ki, 2001; Frenkel, 2001).

Essa concentração não é benéfica em nível regional, dado que não se pode desenvolver um sistema nacional de inovação via sistemas locais de inovação isolados, implicando uma maior concentração de renda, menores encadeamentos regionais, menor número de oportunidades tecnológicas e de complementaridades regionais. A perpetuação das disparidades no desenvolvimento regional pode manter o hiato tecnológico que contribui para um menor ritmo de desenvolvimento do País como um todo.

Deve-se levar em conta que o nível de atividade econômica de um estado ou região parece não se relacionar de forma perfeitamente direta e proporcional com a dimensão de seus setores inovativos, dado que, por exemplo, Minas Gerais tem o terceiro maior PIB do País, e, no entanto, ocupa a sexta posição em termos de produção de inovações. É possível atribuir tal resultado à concentração, em Minas Gerais, de atividades de baixo teor tecnológico, como é o seu setor metalúrgico. Ao contrário do Rio Grande do Sul, que concentra indústrias dinâmicas, com maiores transbordamentos e nas quais os gastos em P\&D são maiores (Tabela 5), de forma que este estado é o segundo na classificação do total dos dispêndios em P\&D. Em suma, os resultados empíricos encontrados neste trabalho vêm corroborar a noção de que o País convive com um sistema nacional de inovação extremamente limitado, o que se reflete no alto grau de concentração das indústrias empregadoras de alta tecnologia nas regiōes Sudeste e Sul, indicando uma precariedade dos fatores estruturais nas demais regióes. Em outras palavras, o arranjo institucional mais desenvolvido de algumas regiōes, que ora se confunde com uma melhor estrutura urbana, contrasta com as limitações e mesmo ausência destes mesmos elementos em outras regiōes/áreas tidas como menos desenvolvidas e até "vazias". Isto é, em parte, reflexo da dinâmica de desenvolvimento/ocupação espacial do País notada desde seu descobrimento. 
Uma política tecnológica regional se faz mister, vez que o desenvolvimento nacional não pode depender apenas do fortalecimento da região polarizada pelo Estado de São Paulo (Albuquerque et al., 2002b). A aproximação de uma distribuição das atividades de alta tecnologia no País, em dados proporcionais, tal como feita neste trabalho, pode auxiliar numa primeira tentativa de formular políticas específicas para localidades distintas. As informações obtidas podem fomentar a tomada de decisão dos planejadores urbanos e econômicos locais, os policy-makers e os empresários, e guiar estratégias de desenvolvimento regional baseado no novo contexto da economia fundamentada na geração e utilização de conhecimentos nos processos produtivos. Ademais, deve-se promover uma maior participação relativa dos setores que atuam próximos da fronteira científica (química, farmacêutica, tecnologia da informação e comunicaçôes) e de setores produtores de bens de capital para que se possa ter uma maior utilização de ativos e insumos tecnológicos que levem a um mais rápido e intensivo progresso tecnológico, atentando-se ao máximo para a diminuição das discrepâncias entre distribuições regionais de atividades industriais e de renda.

\section{Referências bibliográficas}

Abramovitz, M., "Catching up, forging ahead, and falling behind", in Journal of Economic History, 66 (2), p.385-406, jun.,1986.

Acs, Z.; Audretsch, D.B.; Feldman, M.P., "The real effects of academic research", in American Economic Review, v.82, p.363-367, 1992.

Albuquerque, E. M., "National systems of innovation and non-OECD countries: notes about a rudimentary and tentative 'typology", in Revista de Economia Política, 19 (4), p.35-52, out.-dez., 1999.

Albuquerque, E. M.; Simões, R.; Baeza, A.; Campolina, C.; Silva, L., "A distribuição espacial da produção científica e tecnológica brasileira: uma descrição de estatísticas de produção local de patentes e artigos científicos" in Revista Brasileira de Inovação, 1 (2), p.225-251, jul.-dez., 2002a. 
Albuquerque, E. M.; Paula, J.A.; Cerqueira, H.E.A.G., "Inovação tecnológica e desenvolvimento", in Banco de Desenvolvimento de Minas Gerais, Belo Horizonte. Minas Gerais do Século XXI, v.VII. Belo Horizonte: Roma Editora, 2002b, disponível em: <http://www.bdmg.mg.gov.br/produtos/estudo1.asp>. Acesso: 7/2/2004.

Alem, A.C., "A vulnerabilidade externa da economia brasileira: diagnóstico e setores mais atingidos", in Revista do BNDES, 10 (20), p.3-40, 2003.

Audretsch, D.; Feldman, M., "R\&D Spillovers and the geography of innovation and production", in American Economic Review, 86 (3), p.630-640, 1996.

Bacharach, M., Biproportional Matrices and Input-Output Change, Cambridge: Cambridge University Press, 1970.

BRASIL. Governo Federal. Ministério do Desenvolvimento, Indústria e Comércio Exterior-MDIC, Estudo da Competitividade da Indústria Brasileira, Brasília, 1993, disponível em: < http://www.mct.gov.br/mct\%20site/internet/publi/ compet $>$. Acesso: 29/1/2004.

Britto, G., Indústrias de Alta Tecnologia no Brasil: Localização e Dinâmica Regional, 1999. Monografia (Graduação), Ciências Econômicas, Faculdade de Ciências Econômicas, Universidade Federal de Minas Gerais - UFMG, Belo Horizonte, 1999.

Diniz, C.C.; Gonçalves, E., "Possibilidades e tendências locacionais da indústria do conhecimento no Brasil", in Encontro Nacional de Economia, 28, 2000, Campinas. Anais... Campinas: ANPEC, dez., 2000.

, "Economia do conhecimento e desenvolvimento regional no Brasil", in Encontro de Estudos Regionais e Urbanos, 1, 2001, São Paulo. Anais... São Paulo: ABER, dez., 2001.

FAPESP - Fundação de Amparo à Pesquisa do Estado de São Paulo, Indicadores de Ciência, Tecnologia e Inovação em São Paulo - 2001, São Paulo, 2002, disponível em: <http://www2.fapesp.br/indct/indica.htm>. Acesso: 29/1/2004.

Freeman, C., "The 'national system of innovation' in historical perspective", in Cambridge Journal of Economics, 19, p.5-24, 1995.

Frenkel, A., "Why high-technology firms choose to locate in or near metropolitan areas", in Urban Studies, 38 (7), p.1.083-1.101, 2001.

Howells, J.R.L., "Tacit knowledge, innovation and economic geography", in Urban Studies, 39, p 871-884, 2002. 
IBGE - Instituto Brasileiro de Geografia e Estatística, Pesquisa Industrial de Inovação Tecnológica 2000 - PINTEC), Rio de Janeiro, 2002.

Jaffe, A.B.; Trajtenberg, M.l; Henderson, R., "Geographic localization of knowledge spillovers as evidenced by patent citations", in Quarterly Journal of Economics, 108, p.577-598, ago., 1993.

$\mathrm{Ki}, \mathrm{J} . \mathrm{-H}$. , "The role of two agglomeration economies in the production of innovation: a comparison between localization economies and urbanization economies", in Enterprise and Innovation Management Studies, 2 (2), p.103-117, 2001.

Klevorick, A.; Levin, R.; Nelson, R.; Winter, S., "On the sources and significance of inter-industry differences in technological opportunities", in Research Policy, 24 (2), p.185-205, 1995.

Silva, L.; Simões, R.F., "Oportunidades tecnológicas e produção científica: uma análise microrregional para o Brasil", in Revista Latinoamericana de Estudios Urbano-Regionales, Santiago, 90, set., 2004.

Simões, R.F., "Uma proposta de metodologia para estimação de informações fechadas dos censos econômicos: o problema da desagregração para a análise regional", in XI Encontro Nacional da Sociedade Brasileira de Econometria, 1989, Fortaleza. Anais..., Fortaleza: SBE, 1989.

Wajnman, S., Estrutura Demográfica da População Economicamente Ativa e Distribuição de Renda: Brasil - 1970-1980, Dissertação (Mestrado em Demografia) Universidade Federal de Minas Gerais, UFMG, Belo Horizonte, 1995. 